\title{
Cohort maintenance strategies used by The Irish Longitudinal Study on Ageing (TILDA)
}

Orna Donoghue, Margaret Foley, Rose Anne Kenny 
Copyright (C) The Irish Longitudinal Study on Ageing 2017

The Irish Longitudinal Study on Ageing

Lincoln Place

Trinity College Dublin

Dublin 2

Tel: +35318962509

Email: tilda@tcd.ie

Website: www.tilda.ie

https://www.doi.org/10.38018/TildaRe.2017-03 


\section{ABSTRACT}

The Irish Longitudinal Study on Ageing (TILDA) is a large prospective cohort study of the social, economic and health circumstances of community-dwelling adults aged 50 years and over resident in Ireland. As there was no extant panel in Ireland coupling age and address information, all addresses required cold calling at baseline. In this report, we describe the strategies used to retain this cohort over the first three waves of data collection and thereby, provide guidance to new and existing longitudinal cohort studies. The strategies used have been classified into seven broad categories: study identity and bond; study information and impact; adaptable methods of data collection; personnel; tracing, scheduling and contacting; persistence and reminders; incentives and reimbursement. Response rates for each component of the study are: interview (85-90\%), selfcompletion questionnaire (85\%), health assessment $(72-82 \%)$. While we cannot identify the impact of individual strategies, the key strategies that we feel were effective include well-trained personnel, rapport between participants and data collectors, inclusion of a health assessment, provision of feedback and flexibility in data collection.

Key words: attrition; cohort studies; longitudinal studies; prospective studies; retention 


\section{LIST OF ABBREVIATIONS}

CAPI: computer-assisted personal interview

DNA: deoxyribonucleic acid

ELSA: English Longitudinal Study of Ageing

EOL: End-of-Life

GP: general practitioner

MRI: magnetic resonance imaging

SAE: stamped addressed envelope

SCQ: self-completion questionnaire

TILDA: The Irish Longitudinal Study on Ageing 


\section{INTRODUCTION}

Longitudinal cohort studies are conducted to examine cumulative effects and patterns of change over time and to obtain better information about causal relationships, however they are subject to many complexities and challenges including sample attrition and motivation $(1,2)$. Participants are typically asked for a substantial time commitment, often spanning many years. Issues such as sample attrition, where an individual leaves the study (due to death, withdrawal, moving outside study area, etc.), and item non-response, when individuals do not provide certain information, are problematic as they can lead to biased estimates of association. This is particularly so if there is selective attrition of specific subgroups such as those with poor health, in lower socio-economic groups or with specific motivations $(3,4)$.

The Irish Longitudinal Study on Ageing (TILDA) is a large prospective cohort study of the social, economic and health circumstances of 8,504 community-dwelling adults aged 50 years and over (and their spouses of any age) resident in Ireland. It was established to address the challenges and opportunities associated with population ageing and to provide an evidence-base with which to inform policy and practice. Baseline data collection began in 2009 and Wave 3 was completed in December 2015. Sampling and study design are described in Whelan et al (5). The main challenge was that there is no extant panel coupling age and address information in Ireland. Therefore, a stratified twostaged clustered procedure was used to sample from the Irish GeoDirectory, a listing of all residential addresses in the Republic of Ireland, compiled by An Post (the Irish Postal Service) and Ordnance Survey Ireland. A total of 640 clusters were randomly sampled from 3,155 clusters nationwide with a probability proportional to size and stratified by geographic, and demographic factors. In each cluster, a random sample of 40 addresses was chosen, and household residents aged 50 years and over and their spouses/ partners (of any age) who were cognitively intact were eligible to participate. As the ages of residents were unknown, all addresses required cold calling by social interviewers, resulting in a household response rate of $62 \%$. This was a time-consuming and costly process, making cohort maintenance in subsequent waves a high priority.

In this report, we describe the strategies used to retain this cohort over the first three waves of data collection. These strategies have been modified and improved over time as the most effective approaches have been identified. The purpose of this report is to provide guidance to new and existing longitudinal cohort studies, and to enable them to take and 
adapt the strategies outlined here that best suit their own circumstances. While we present these in the context of an ageing study, the majority can be applied across a range of cohorts. 
TILDA uses three modes of data collection: 1) a computer-assisted personal interview (CAPI), conducted in the home by trained interviewers; 2) a paper-based self-completion questionnaire (SCQ), completed privately by the participant; and 3) a comprehensive health assessment, conducted by trained research nurses in a health centre or a modified version conducted in the participant's home. The CAPI and SCQ are included at each wave, while the health assessment is conducted at every second wave (see Figure 1). Wave 3 included brain magnetic resonance imaging (MRI) for a sub-sample of participants while in non-health assessment waves, interviewers conduct two physical function tests during the CAPI (grip strength, Timed Up-and-Go).

The retention strategies used have been classified into seven broad categories: project identity and bond; study information and impact; adaptable methods of data collection; personnel; tracing, scheduling and contacting; persistence and reminders; incentives and reimbursements.

Figure 1. Timelines and modes of data collection at each wave of TILDA
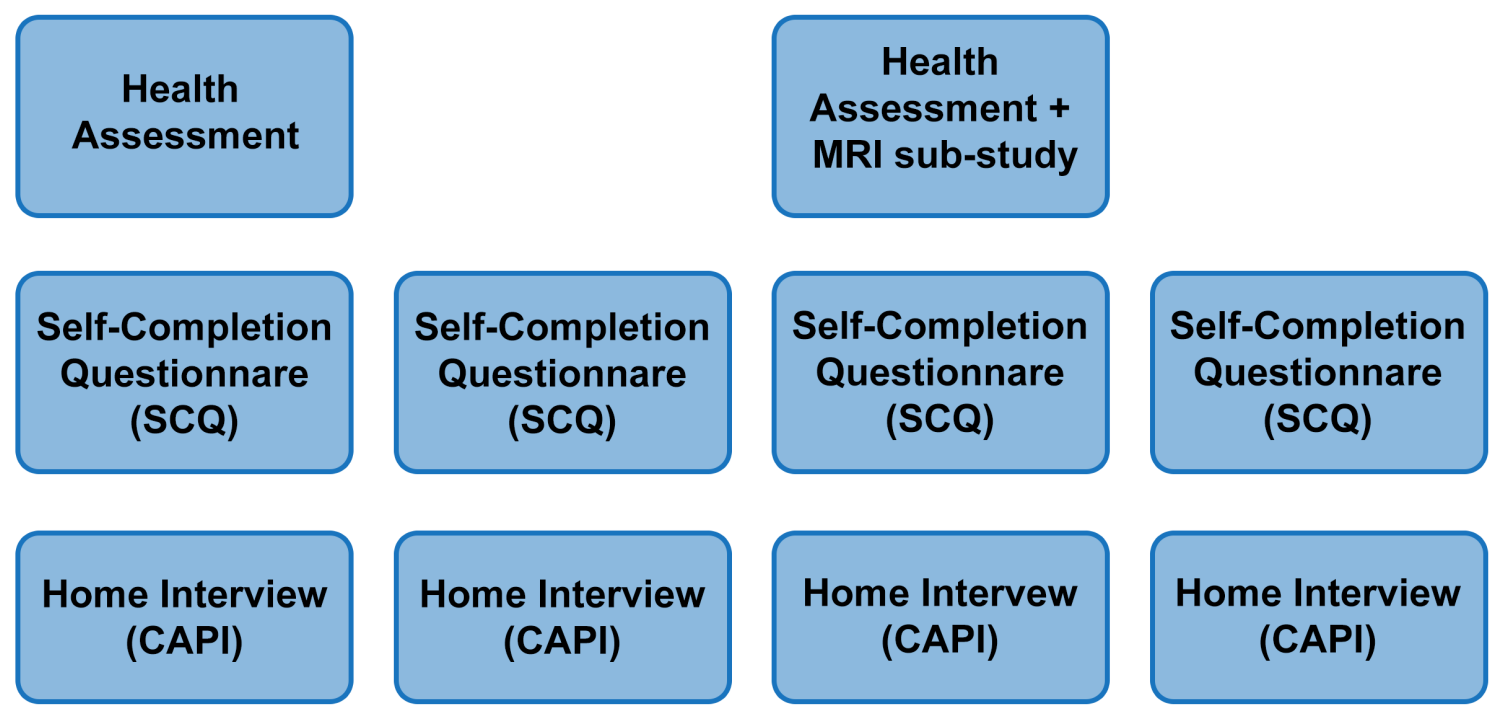

Wave 1 2009-2011
Wave 2

2012
Wave 3

2014-2015
Wave 4 2016 


\section{Project identity and bond}

Creating a bond between participants and the study team is vital. This was done by establishing a clear identity, purpose and logo for the study and maintaining regular contact between participants and the Principal Investigator through newsletters, Christmas cards and letters notifying participants of upcoming waves (Table 1). Participants were also given a Trinity College Dublin certificate of participation in Wave 1. Trinity College Dublin is the oldest and most prestigious university in Ireland and therefore, a certificate was extremely popular, with many participants displaying it in their homes. In 2016, participants were invited to an event hosted in Trinity College to celebrate 10 years of the study. This event recognised the significant contribution of participants and highlighted the impact of the research findings to date. A huge emphasis is placed on ensuring that participants not only enjoy their experiences in TILDA but also have opportunities to provide feedback and suggestions and know that these are valued and acknowledged. This input can be provided directly to the study team via mail, email, phone, or it can be provided to the data collectors. This helps to engage participants with the study and provides valuable information for the study team. Appreciation for participants' contributions is highlighted in letters, cards, newsletters, reports and publications. 
Table 1. Strategies and Activities Used to Create a Project Identity and Participant Bond with the Study

\begin{tabular}{|c|c|}
\hline Strategy & Activities \\
\hline $\begin{array}{l}\text { Create project } \\
\text { identity and develop } \\
\text { participant bond with } \\
\text { the study }\end{array}$ & $\begin{array}{l}\text { Clear overarching aim: 'To make Ireland the best place in the } \\
\text { world to grow old'; } \\
\text { Use TILDA logo and colours on all reports, correspondence } \\
\text { and mementos (pens, keyrings); } \\
\text { Provide certificates of participation from Trinity College Dublin; } \\
\text { Host event for participants to celebrate } 10 \text { years of the study; } \\
\text { Highlight importance of each participant in all communications, } \\
\text { reports and publications; } \\
\text { Welcome feedback and input from participants via mail, email, } \\
\text { phone or to the data collectors or using the comment section in } \\
\text { self-completion questionnaire; } \\
\text { Acknowledge and respond to comments and suggestions from } \\
\text { participants in a timely manner. }\end{array}$ \\
\hline $\begin{array}{l}\text { Maintain regular } \\
\text { contact with } \\
\text { participants }\end{array}$ & $\begin{array}{l}\text { Send annual Christmas cards; } \\
\text { Send 1-2 participant newsletters per year to share information } \\
\text { about recent research findings, policy impacts, study } \\
\text { development, staff bios, etc; } \\
\text { Include message from Principal Investigator in newsletters, } \\
\text { Christmas cards and letters notifying participants about } \\
\text { upcoming waves. }\end{array}$ \\
\hline
\end{tabular}




\section{Study information and impact}

The strategies and activities which fall within this category are described in Table 2. Advance letters are sent prior to each new wave to notify participants about upcoming interviews. Information booklets for different interview types (self, proxy or End-of-Life (EOL) interviews) and different components of the study (health centre assessment, home assessment, donating blood and hair samples, MRI) are also provided, along with assurances of confidentiality and TILDA contact details if participants would like further information. In particular, the TILDA research nurses are available to discuss what the health assessment entails and this was particularly relevant when it was first introduced at Wave 1 . The research results and policy impacts are published and regularly presented at conferences, to government and non-government organisations and in educational courses. TILDA also work with Trinity Communications Office to issue press releases and engage with media on specific research findings and project outcomes. This highlights the importance and relevance of the study to participants and the general public and promotes continued participation. 
Table 2. Strategies and Activities Used to Provide Study Information and Highlight Study Impact to Participants

\begin{tabular}{|c|c|}
\hline Strategy & Activities \\
\hline $\begin{array}{l}\text { Send advance letters } \\
\text { at least one week } \\
\text { prior to interviewer } \\
\text { contact at each wave }\end{array}$ & $\begin{array}{l}\text { Highlight importance of the study and valuable contribution of } \\
\text { participants; } \\
\text { Provide clear indication of upcoming requirements, and provide } \\
\text { assurances of confidentiality. }\end{array}$ \\
\hline $\begin{array}{l}\text { Provide sufficient } \\
\text { information to allow } \\
\text { informed consent }\end{array}$ & $\begin{array}{l}\text { Provide separate information booklets for interviews (self, } \\
\text { proxy, EOL), health assessments, blood and hair sample } \\
\text { collection and MRI sub-study outlining what is involved, time } \\
\text { commitment, etc; } \\
\text { Participants can request a call-back from a TILDA research } \\
\text { nurse to discuss the health assessment; } \\
\text { Provide a participants section with FAQs on TILDA website; } \\
\text { Provide assurances of confidentiality on all materials; } \\
\text { Maintain data protection and confidentiality in all project } \\
\text { activities. }\end{array}$ \\
\hline $\begin{array}{l}\text { Provide access to } \\
\text { TILDA staff to answer } \\
\text { queries, provide } \\
\text { suggestions, etc. }\end{array}$ & $\begin{array}{l}\text { Provide TILDA contact details on all correspondence, thus } \\
\text { providing an open invitation for participants to contact TILDA; } \\
\text { Include comments section at end of the SCQ; } \\
\text { Provide timely response to all queries from participants. }\end{array}$ \\
\hline $\begin{array}{l}\text { Publicise research } \\
\text { and policy impacts of } \\
\text { the study }\end{array}$ & $\begin{array}{l}\text { Publish journal articles, research briefs and topic reports; } \\
\text { Present research output and policy impacts to government, } \\
\text { non-governmental organisations, older adult forums, etc; } \\
\text { Host policy conferences to promote engagement with } \\
\text { policymakers; } \\
\text { Issue press releases with Trinity Communications Office; } \\
\text { Provide details of all research output and study outcomes on } \\
\text { TILDA website; } \\
\text { Highlight research output and project activities on Twitter; } \\
\text { Engage with national and international media (press, radio and } \\
\text { television) about research reports and policy impacts; } \\
\text { Publish a series of TILDA articles in the Irish Independent } \\
\text { Health and Wellbeing Supplement (national newspaper); } \\
\text { Contribute to Successful Strategies for Ageing, a Massive } \\
\text { Online Open Course delivered on FutureLearn platform. }\end{array}$ \\
\hline
\end{tabular}


Adaptable data collection to facilitate participants' needs and minimise participant burden

As participants' abilities and circumstances change, it is important to adapt the data collection methods to allow them to continue their involvement in the study, therefore assisted interviews, proxy interviews, nursing home interviews, EOL interviews and a modified home-based health assessment are available (Table 3). While the time required to complete each component of the study varies, the average durations are: self-interview (1.5 hours), proxy interview (1 hour), EOL interview (40 mins), SCQ (30 minutes) and health assessment ( 3 hours). Questionnaires are designed to minimise the time required for completion and thus reduce participant burden. For example, in households with at least two participants, the 'financial respondent' is asked about family finance while the 'family respondent' is asked about family circumstances to avoid duplication of questions. Information provided in previous waves is also fed forward to the current wave and participants are asked to clarify any change in circumstances. This makes the interview more personal and reduces the sense of frustration at having to repeat the same information at each wave. Breaks are taken as required and interviews can be completed over two separate occasions if necessary. 
Table 3. Strategies and Activities Used to Ensure Adaptable Data Collection to Facilitate Participants' Needs and Minimise Participant Burden

\begin{tabular}{|c|c|}
\hline Strategy & Activities \\
\hline $\begin{array}{l}\text { Adapt mode of data } \\
\text { collection based } \\
\text { on participant } \\
\text { circumstances }\end{array}$ & $\begin{array}{l}\text { Conduct self-interview (if participant can complete interview } \\
\text { themselves); } \\
\text { Conduct assisted interview (if participant needs assistance with } \\
\text { some questions); } \\
\text { Conduct proxy interview (if participant is unable to complete } \\
\text { interview due to physical or cognitive impairment and } \\
\text { consented to a proxy interview in a previous wave); } \\
\text { Conduct End-of-Life interview (if participant has passed away); } \\
\text { Conduct interview in participant's home, nursing home or other } \\
\text { suitable location; } \\
\text { For nursing home interviews, seek assistance from family to } \\
\text { gain access to nursing home and nursing home manager; } \\
\text { Conduct modified home-based health assessment (if } \\
\text { participant is unable or unwilling to travel to health centre). }\end{array}$ \\
\hline $\begin{array}{l}\text { Adapt questionnaires } \\
\text { and assessments to } \\
\text { reduce participant } \\
\text { burden }\end{array}$ & $\begin{array}{l}\text { Where feasible, feed forward information provided in previous } \\
\text { wave (not used in proxy or EOL interviews to maintain } \\
\text { participant confidentiality); } \\
\text { Ask the 'financial respondent' questions about family finances } \\
\text { (if minimum of two participants in household); } \\
\text { Ask the 'family respondent' questions about family } \\
\text { circumstances (if minimum of two participants in household); } \\
\text { Allow breaks during interview/health assessment as required; } \\
\text { Complete interview over two days if necessary; } \\
\text { Provide refreshments at health assessment centre. }\end{array}$ \\
\hline
\end{tabular}




\section{Personnel}

All staff receive training to ensure professional, respectful and timely interactions (inperson, telephone and written) with participants (Table 4). Interviewers and research nurses undergo intensive training to ensure that they follow standardised protocols during data collection and are fully prepared to cope with a range of circumstances. They must also pass an accreditation before they begin data collection and quality control procedures continue throughout fieldwork. In addition, interviewers complete a health assessment themselves so that they are fully aware of what it entails and therefore, can discuss it with participants. Where possible (and unless otherwise requested), interviewers are assigned to the same participants at subsequent waves to maintain continuity in this relationship. Debrief sessions and social lunch events are held after each pilot study and fieldwork phase, to obtain feedback and suggestions from interviewers while nurses attend regular meetings and study days. Feedback channels are also maintained throughout the fieldwork period though dedicated email and phone support. Interviewers and nurses are employed for specific periods during the lifetime of the study however they are viewed as essential members of the research team. 
Table 4. Strategies and Activities Used to Ensure Appropriate Personnel Interactions with Participants

\begin{tabular}{l|l}
\multicolumn{1}{c}{ Strategy } & \multicolumn{1}{c}{ Activities } \\
Provide identification & Interviewers and research nurses carry photo ID cards; \\
forllectors & $\begin{array}{l}\text { Interviewers provide a letter to local police stations to inform } \\
\text { them about upcoming waves of data collection. }\end{array}$ \\
Ensure well-trained and & Interviewers attend 2-3 days of intensive training prior to \\
competent interviewers & each wave; \\
& Include presentation from Principal Investigator at training; \\
& Cover study design and purpose, interview types, \\
& questionnaire content, physical and cognitive measures, \\
& fieldwork procedures, data protection at training; \\
& Provide standardised protocols and emphasise importance \\
& of adherence to these; \\
& Provide training to deal with emotional reactions to specific \\
& questions e.g. mental health issues, End-of-Life issues; \\
& Provide practical training on physical and cognitive \\
& measures; \\
& Ensure each interviewer successfully completes \\
& accreditation before beginning fieldwork; \\
& Maintain ongoing quality control and individual and group \\
& feedback throughout data collection; \\
Invite interviewers to attend health assessment conducted & by a TILDA research nurse; \\
Hold interviewer debrief after pilot study and on completion \\
of fieldwork; \\
Provide dedicated email and phone support for interviewers \\
throughout fieldwork.
\end{tabular}




\begin{tabular}{|c|c|}
\hline Strategy & Activities \\
\hline $\begin{array}{l}\text { Ensure well-trained and } \\
\text { competent research } \\
\text { nurses }\end{array}$ & $\begin{array}{l}\text { Research nurses attend } 4 \text { weeks of training and practice } \\
\text { including assessments on volunteers; } \\
\text { Ensure nurses have approved phlebotomy training and } \\
\text { experience; } \\
\text { Ensure nurses attend Basic Life Support (BLS) course which } \\
\text { includes Cardio Pulmonary Resuscitation (CPR) and the use } \\
\text { of an Automated Electrical Defibrillator (AED); } \\
\text { Provide standardised data collection protocols and } \\
\text { emphasise importance of adherence to these; } \\
\text { Ensure each nurse successfully completes accreditation } \\
\text { before beginning data collection; } \\
\text { Maintain ongoing quality control and individual and group } \\
\text { feedback throughout data collection; } \\
\text { Provide standardised protocols to deal with situations that } \\
\text { require immediate medical attention; } \\
\text { Provide } 24 \text { hour access to Medical Director if medical } \\
\text { emergency or medical advice required during data } \\
\text { collection; } \\
\text { Hold regular meetings and study days to provide } \\
\text { clarification, updates, additional training, etc. }\end{array}$ \\
\hline $\begin{array}{l}\text { Ensure well-trained and } \\
\text { competent research and } \\
\text { admin staff }\end{array}$ & $\begin{array}{l}\text { Maintain a high standard and professionalism in quality and } \\
\text { content of all study materials; } \\
\text { Provide training on appropriate telephone manner; } \\
\text { Record clear outcomes and actions after each } \\
\text { communication with participants to ensure timely completion. }\end{array}$ \\
\hline $\begin{array}{l}\text { Maintain continuity of } \\
\text { interviewer-participant } \\
\text { relationship }\end{array}$ & $\begin{array}{l}\text { Assign same interviewer to participants at subsequent } \\
\text { waves (if possible and unless otherwise requested). }\end{array}$ \\
\hline
\end{tabular}




\section{Tracing, contacting and scheduling}

A number of strategies and activities relating to tracing, contacting participants and scheduling interviews and assessments are described in Table 5. An up-to-date contact database (with participant names, addresses, phone numbers and email addresses) is crucial to enable tracking of participants throughout the study. Participants are asked to notify TILDA of a change in contact details (directly, using change of address cards provided or via the TILDA website) however, interviewers may also acquire this information when tracing participants. Details are also confirmed at each contact with the participant and during interviews and health assessments. Historical contact details are retained along with any information about the best way to contact participants e.g. evenings only, not during summer months as abroad at that time, etc. At each wave, participants are asked to provide details of 'stable contacts', usually family members or friends who can assist if there are difficulties contacting a participant directly.

Interviewers visit participants' houses to arrange an interview a minimum of one week after the advance letters are posted. Previous studies showed that participants are less likely to refuse participation during a face-to-face conversation compared to telephone contact (6). As multiple forms of contact are most effective in retaining participants (7), interviewers then follow a standardised contact strategy if contact is not made (see Figure 2). This involves leaving calling cards, multiple call-backs (in-person and by phone) on various days and at various times, contact with family members and nursing home manager if the participant is now resident in a nursing home and electronic recording of all outcomes.

During the interview, participants are asked if they would like to have a health assessment and if they agree, the interviewer immediately contacts the health centre administrator on behalf of the participant. If it is not possible to arrange a health assessment appointment at this time, multiple contacts by telephone and letter are used to schedule the appointment. Flexibility is provided when scheduling interviews and health assessments to accommodate any commitments that participants and/or their carers have in relation to work or family and to find the most suitable date and time. All appointments are confirmed by phone or mail to reduce non-attendance although late cancellations do still occur.

A tracking file is used to record participants' involvement at each wave e.g. date of completion of CAPI, SCQ and health assessment, location of interview and health assessment, type of interview, reasons for non-completion, etc. TILDA link to the Death Registration Records managed by the General Register Office to confirm all reported deaths and identify outcomes for participants who have withdrawn or who have been lost to follow-up. This tracking file is essential for reports and papers which use longitudinal analysis. 
Table 5. Strategies and Activities Used during Tracing, Contacting Participants and Scheduling Interviews and Assessments

\begin{tabular}{|c|c|}
\hline Strategy & Activities \\
\hline $\begin{array}{l}\text { Maintain up-to-date } \\
\text { contact database }\end{array}$ & $\begin{array}{l}\text { Record participant names, addresses, phone numbers and } \\
\text { email addresses; } \\
\text { Request that participants notify TILDA of a change in contact } \\
\text { details by phone, post, email, using change of address cards } \\
\text { provided or through the change of address link on the TILDA } \\
\text { website; } \\
\text { Confirm participant contact details during interviews and, } \\
\text { health assessments and on all correspondence; } \\
\text { Maintain regular contact with participants i.e. every 6-12 } \\
\text { months; } \\
\text { Record contact details of two 'stable contacts' (i.e. close family } \\
\text { or friends) at each wave. }\end{array}$ \\
\hline $\begin{array}{l}\text { Ensure in-person } \\
\text { and repeated contact } \\
\text { strategy for interview }\end{array}$ & $\begin{array}{l}\text { Attempt face-to-face first contact with participant; } \\
\text { Leave calling card with interviewer contact details if no contact } \\
\text { is made; } \\
\text { Attempt multiple contacts (up to 5) on different days, at } \\
\text { different times, etc. to allow for work or social commitments; } \\
\text { Follow participants who have moved to another house or } \\
\text { nursing home in the Republic of Ireland and Northern Ireland; } \\
\text { Confirm interview appointment by phone; } \\
\text { Record details and outcomes of all contacts attempted in } \\
\text { electronic format. }\end{array}$ \\
\hline $\begin{array}{l}\text { Ensure repeated } \\
\text { contact strategy } \\
\text { and confirmation for } \\
\text { health assessment }\end{array}$ & $\begin{array}{l}\text { Interviewer contacts TILDA if participant agrees to health } \\
\text { assessment during the interview; } \\
\text { Where possible, arrange health assessment at this time; } \\
\text { If this is not possible, attempt multiple contacts on different } \\
\text { days, at different times, etc. to allow for working or social } \\
\text { commitments; } \\
\text { Post letter if no contact is made via telephone; } \\
\text { Schedule and re-schedule appointments as necessary; } \\
\text { Confirm appointment by post } 2 \text { weeks before appointment; } \\
\text { Confirm appointment by telephone in week before } \\
\text { appointment. }\end{array}$ \\
\hline
\end{tabular}


Strategy

Allow flexible scheduling

\section{Activities}

Provide day, evening or weekend appointments for interviews;

Provide appointments in health assessment centre between 8

am and $8 \mathrm{pm}$, Monday to Saturday;

Provide day, evening or weekend appointments for home-

based health assessments.

\begin{tabular}{l|l} 
Maintain accurate and & Record outcomes for all participants at each wave; \\
up-to-date tracing file & Link with Death Registration Records at General Register \\
& Office to confirm notified deaths and identify outcomes for \\
individuals who have withdrawn or been lost to follow-up.
\end{tabular}




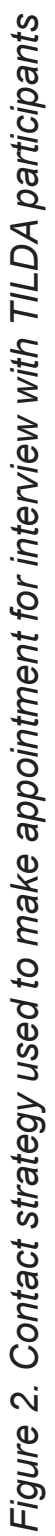

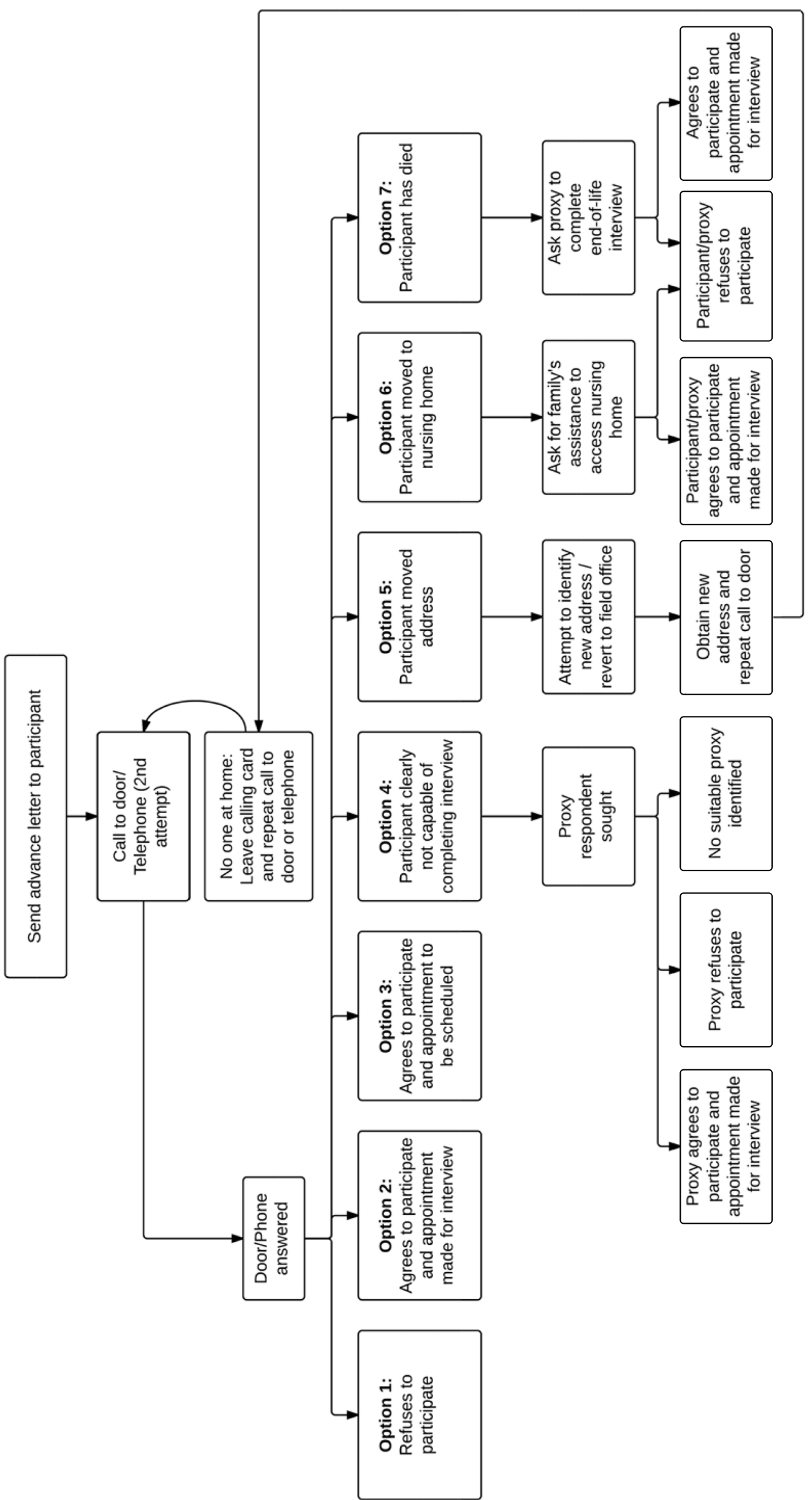




\section{Persistence and reminders}

It is important to ensure that participants are given every opportunity to take part and to monitor reasons for refusals/withdrawals (Table 6). Participants who choose not to participate at a particular wave ('soft refusals') or who cannot be contacted continue to be followed up at future waves. Participants who request to withdraw are contacted by the Project Manager to thank them for their contributions and to confirm their request. Reasons for refusal and withdrawal are also recorded to identify if follow-up is required and if further attrition can be prevented. Participation in the health assessment and SCQ are continually monitored to maximise response rates (see scheduling strategy for health assessment above). All SCQs returned by participants to TILDA are checked against completed interviews. Participants who do not return their SCQ within 3 months receive reminder phone calls and a new SCQ and stamped addressed envelope (SAE) is posted if required. After five unsuccessful contact attempts, reminder letters are posted to participants with a new SCQ and SAE. In a small number of cases, interviewers have collected and posted SCQs for participants who may not have easy access to a post office.

Table 6. Strategies and Activities Used to Ensure Appropriate Levels of Persistence and to Provide Reminders to Participants

\begin{tabular}{|c|c|}
\hline Strategy & Activities \\
\hline $\begin{array}{l}\text { Conduct reminder } \\
\text { phone calls to } \\
\text { maximise SCQ } \\
\text { response rates }\end{array}$ & $\begin{array}{l}\text { Encourage participants to complete the SCQ; } \\
\text { Conduct repeated reminder calls (up to } 10 \text { attempts) on various } \\
\text { days and at different times; } \\
\text { Re-post SCQ and stamped addressed envelope (SAE) if } \\
\text { mislaid; } \\
\text { Send reminder letter, SCQ and SAE if participants are not } \\
\text { contacted after } 5 \text { telephone calls; }\end{array}$ \\
\hline $\begin{array}{l}\text { Monitor refusals and } \\
\text { withdrawals }\end{array}$ & $\begin{array}{l}\text { Participants can delay interview or health assessment if a later } \\
\text { date during fieldwork is more suitable; } \\
\text { Follow up on 'soft refusals' at all subsequent waves; } \\
\text { Project Manager contacts potential withdrawals to thank them } \\
\text { for their participation and to confirm their request; } \\
\text { Record the reasons for refusals and withdrawals for analysis } \\
\text { and follow-up if necessary; } \\
\text { Project Manager contacts participants if they report } \\
\text { dissatisfaction with any aspect of the study. }\end{array}$ \\
\hline
\end{tabular}




\section{Incentives and reimbursements}

In TILDA, a number of strategies are used to incentivise participants to take part in the study and to ensure that participants are not bearing any cost to participate (Table 7). A major incentive for participants is that they and their GPs (with their permission) receive the results and interpretation of a number of clinical tests conducted during the health assessment i.e. blood pressure, weight, cholesterol, visual acuity and bone density based on a heel ultrasound. Brain scan reports were also sent to GPs for participants in the MRI sub-study and these indicate if a follow-up clinical scan is recommended for further investigation. As the health assessments and MRIs take place in Dublin (also Cork in Wave 1), participants are often unable to travel to and from these locations in one day. Therefore, travel and overnight accommodation is arranged for participants and all expenses are reimbursed to ensure that they are not out-of-pocket. Participants are also given a $€ 20$ money order for completing a self, proxy or EOL interview. Many rural post offices and banks in Ireland have closed in recent years, therefore postal money orders were chosen over cheques/bank drafts as they can be cashed in local shops or post offices. Pilot work showed that higher incentives ( $€ 25$ versus $€ 10$ ) led to higher cooperation, especially in areas where baseline participation was low (8), however, further increases to $€ 40$ did not improve response rates.

Table 7. Strategies and Activities Used to Provide Incentives and Reimbursements to Participants

\begin{tabular}{l|l}
\multicolumn{1}{c|}{\begin{tabular}{c}
\multicolumn{1}{c}{ Strategy } \\
$\begin{array}{l}\text { Provide monetary } \\
\text { incentives }\end{array}$
\end{tabular}} & $\begin{array}{l}\text { Provide a postal money order for } € 20 \text { for completion of self, } \\
\text { proxy or End-of-Life interview. }\end{array}$ \\
$\begin{array}{l}\text { Provide feedback on } \\
\text { health assessment }\end{array}$ & $\begin{array}{l}\text { Provide results and interpretation of blood pressure, } \\
\text { cholesterol, weight, visual acuity, heel bone density to } \\
\text { measures }\end{array}$ \\
$\begin{array}{l}\text { participant and participant's GP (if they provide permission for } \\
\text { this); } \\
\text { Provide scan results of participants in the MRI sub-study } \\
\text { to participant's GP, indicating if further clinical scan is } \\
\text { recommended; }\end{array}$ \\
$\begin{array}{ll}\text { Reimburse expenses } \\
\text { incurred to attend } \\
\text { health centre }\end{array}$ & $\begin{array}{l}\text { health centre assessment; } \\
\text { Reimburse travel, accommodation and subsistence expenses } \\
\text { to ensure participants are not out-of-pocket. }\end{array}$ \\
\hline
\end{tabular}




\section{Ethical issues}

Ethical approval for each wave was obtained from the Faculty of Health Sciences Research Ethics Committee at Trinity College Dublin. Ethical approval for the MRI substudy was obtained from the St James's Hospital Research Ethics Committee. Information booklets are provided and participants provide separate written consent to participate in the interview and each component of the health assessment (physical assessment, blood sample collection, bloods results to be sent to GP, extraction and storage of DNA, etc.). Participants may refuse to answer specific questions or take part in specific components of the study at any stage. All data are stored and used according to established data protection requirements. Contact details and other identifiable information are only accessible to staff requiring access for project activities. 


\section{RESULTS}

Response rates for each component of the study over the first three waves are provided in Table 8. At Wave 1, $72 \%$ of participants completed a health assessment and $15 \%$ of these selected a home-based assessment. At Wave 3, 82\% of participants who completed an interview themselves, completed a health assessment, with $20 \%$ completing this in their own homes. During Wave 3, attempts were made to contact 1,188 participants to remind them to return SCQs. Of these, 1,024 participants were contacted successfully by telephone and 427 SCQs were returned (35.9\%).

Table 8. Response Rates for Waves 1, 2 and 3

\begin{tabular}{c|c|c|c}
\hline & Wave 1 & Wave 2 & Wave 3 \\
\hline CAPI & $\mathrm{N}=8,504$ & $\mathrm{~N}=7,375(90 \%)$ & $\mathrm{N}=6,566(85 \%)$ \\
\hline Self a & $\mathrm{n} / \mathrm{a}$ & $\mathrm{N}=80(79 \%)$ & $\mathrm{N}=121(62 \%)$ \\
\hline Proxy $^{\mathrm{b}}$ & $\mathrm{n} / \mathrm{a}$ & $\mathrm{N}=160(84 \%)$ & $\mathrm{N}=215(83 \%)$ \\
\hline EOL $^{\mathrm{c}}$ & $\mathrm{N}=7,196(85 \%)$ & $\mathrm{N}=6,274(85 \%)$ & $\mathrm{N}=5,569(85 \%)$ \\
\hline SCQ $^{{ }^{d}}$ &
\end{tabular}

Health assessment

\begin{tabular}{c|c|c|c} 
Self ${ }^{d}$ & $\mathrm{~N}=6,150(72 \%)$ & n/a & $\mathrm{N}=5,364(82 \%)$ \\
\hline Proxy $^{\mathrm{e}}$ & n/a & n/a & $\mathrm{N}=27(22 \%)$ \\
\hline
\end{tabular}

CAPI, computer assisted personal interview; EOL, End-of-Life; SCQ, self-completion questionnaire.

a Self-interview response rates are based on the eligible number of participants at each wave i.e. those still participating and cognitively capable of completing a self-interview.

b Proxy interviews are required if a participant is unable to complete an interview themselves due to physical or cognitive impairment. Proxy response rates are based on the number of participants requiring a proxy interview (note: due to a change in category labelling at Wave 3 , the Waves 2 and 3 response rates are not directly comparable).

c EOL interviews are sought if a participant passes away. Depending on the timing of death, the EOL interview can be completed in the current wave or if necessary, it can be carried over to the subsequent wave if this is preferable to the EOL respondent. For Wave 2, EOL response rate is based on (Number of interviews completed during Wave 2) / [(Deaths at Wave 2 - Deaths to be followed up at Wave 3)]. For Wave 3, EOL response rate is based on (Number of interviews completed during Wave 3) / [(Deaths carried over from Wave 2) + (Deaths during Wave 3 - Deaths to be followed up at Wave 4)]

$\mathrm{d}$ The denominator for the SCQ and health assessment response rates is the number of participants who completed a selfinterview.

e The denominator for the proxy health assessment response rate is the number of participants who required a proxy interview.

Note: New participants are eligible if they were aged 50 years or over and resident in the selected household at baseline, if they were a spouse/partner (of any age) of an eligible respondent at baseline or if they are a new spouse/partner of an eligible participant.

Table 9 shows characteristics of participants who took part in one, two or three waves. The most notable difference was that participants who took part in all waves were more likely to have tertiary level education and less likely to be aged 75 years and over compared to 
those who took part in either one or two waves. Over one-quarter (27\%) of 'soft refusals' and no contacts at Wave 2 returned to the study and participated in Wave 3. During Wave 3 , approximately $40 \%$ of withdrawals contacted by the Project Manager clarified that they were willing to be contacted at a later time and were therefore, re-classified as 'soft refusals'. The most common reasons for refusal and withdrawal include bad time for personal reasons, too ill, too distressed, not interested and too busy. By the end of Wave 3, 199 new participants joined the study (i.e. those who were eligible but did not participate in Wave 1 or who married an eligible participant since Wave 1), while 698 (8.0\%) have permanently withdrawn and 509 (5.8\%) participants have died.

Table 9: Characteristics of Participants Who Have Completed One Wave (Wave 1 Only), Two Waves (Waves 1 and 2 or Waves 1 and 3) and Three Waves (Waves 1, 2 and 3) of Data Collection

\begin{tabular}{|c|c|c|c|}
\hline & \multicolumn{3}{|c|}{ Participated in: } \\
\hline & $\begin{array}{l}\text { One wave } \\
(n=808)\end{array}$ & $\begin{array}{l}\text { Two waves } \\
(n=1,004)\end{array}$ & $\begin{array}{c}\text { Three waves } \\
(n=6,192)\end{array}$ \\
\hline \multicolumn{4}{|l|}{ Age group (years) } \\
\hline$<50$ & $31(3.8)$ & $32(3.2)$ & $265(4.3)$ \\
\hline $50-64$ & $418(51.7)$ & $523(52.1)$ & $3,632(58.7)$ \\
\hline $65-74$ & $210(26.0)$ & $250(24.9)$ & $1,573(25.4)$ \\
\hline$\geq 75$ & $149(18.4)$ & $199(19.8)$ & $722(11.7)$ \\
\hline \multicolumn{4}{|l|}{ Sex } \\
\hline Male & $354(43.8)$ & $404(40.2)$ & $2,747(44.4)$ \\
\hline Female & $454(56.2)$ & $600(59.8)$ & $3,445(55.6)$ \\
\hline \multicolumn{4}{|l|}{ Educational attainment } \\
\hline Primary level & $329(40.8)$ & $395(39.3)$ & $1,543(24.9)$ \\
\hline Secondary level & $296(36.7)$ & $387(38.6)$ & $2,589(41.8)$ \\
\hline Tertiary level & $181(22.5)$ & $222(22.1)$ & $2,059(33.3)$ \\
\hline \multicolumn{4}{|l|}{ Marital status } \\
\hline Married & $555(68.7)$ & $683(68.0)$ & $4,506(72.8)$ \\
\hline Single & $76(9.4)$ & $89(8.9)$ & $543(8.8)$ \\
\hline Widowed & $40(5.0)$ & $65(6.5)$ & $420(6.8)$ \\
\hline Divorced & $137(17.0)$ & $167(16.6)$ & $723(11.7)$ \\
\hline \multicolumn{4}{|l|}{ Living status } \\
\hline Lives alone & $178(22.0)$ & $225(22.4)$ & $1,206(19.5)$ \\
\hline Lives with others & $630(78.0)$ & $779(77.6)$ & $4,986(80.5)$ \\
\hline \multicolumn{4}{|l|}{ Location } \\
\hline Dublin (city/county) & $181(22.4)$ & $248(24.7)$ & $1,477(23.9)$ \\
\hline Other town & $222(27.5)$ & $309(30.8)$ & $1,707(27.6)$ \\
\hline Rural area & $405(50.1)$ & $447(44.5)$ & 3,008 (48.6) \\
\hline
\end{tabular}

Note: this table includes participants who were eligible for a self-interview at each wave (i.e. it excludes those who died or required a proxy interview). 
Response rates achieved in the first three waves of TILDA compare favourably with response rates of $73-82 \%$ for Waves 1-4 of the English Longitudinal Study on Ageing (ELSA) (9-12) and $82-89 \%$ for Waves 1-9 of the Health and Retirement Survey in the United States (13). SCQ response rates are also similar to those reported in ELSA (87$90 \%)(14,15)$. The high response rates in this sample are likely due to a combination of factors, also highlighted in other studies: participant connection with the study and an established university, frequent contact with participants, well-trained, enthusiastic and committed staff, pre-notification by letter, flexibility in scheduling interviews and health assessments, repeated contacts, provision of SAEs for SCQs, multiple mailouts, incentives, maintaining an up-to-date contact database and availability of staff to discuss the study with participants $(4,16,17)$. While we cannot identify the most effective strategy, we feel that the two biggest contributors in TILDA are the rapport between participants and study personnel and the opportunity to attend and receive feedback for the health assessment.

TILDA interviewers and research nurses are professional, enthusiastic and considerate of participants' circumstances while also being committed to the study and encouraging ongoing participation. This rapport is evidenced by letters and cards received from participants, requests for the same interviewer at subsequent waves and anecdotes about the welcome provided by participants to interviewers and nurses visiting their homes. This bond with the study and study personnel is also an important contributor to maximising proxy and EOL interview response rates as family/friends usually agree to complete these because of the importance that the original participant assigned to the study. Regular media coverage also highlights the relevance of their participation in the study and fosters a sense of pride and satisfaction about their contributions to ageing research in Ireland.

The health assessment is very popular and a major incentive for participation, particularly as participants have the undivided attention of a research nurse for approximately 3 hours. Frailer individuals typically select home-based health assessments $(18,19)$, and this number increased in Wave 3, highlighting that the inclusion of this modified option is vital to cater for this ageing cohort. It was repeatedly emphasised that this is a health assessment and not a 'health check', however despite these efforts, some participants continued to view this as an opportunity to get a clean bill of health. It is possible that this is driven by the two-tier healthcare system in Ireland, where there is a mix of both public and private healthcare providers. While TILDA do provide limited results from the health 
assessment, these are mainly from easily interpretable clinical tests and therefore it was thought that this would not significantly influence innovative research. There is no direct intervention to change a participant's habits, however information leaflets on lifestyle changes are also available at the health centre and implications of research for successful ageing are provided in newsletters and on the TILDA website.

However, the ethical considerations around disclosing individual results (20) did arise when a high prevalence of undiagnosed atrial fibrillation was detected on electrocardiogram readings obtained at Wave 1 (21). Atrial fibrillation increases the risk of stroke (22) but can be controlled with medication so awareness and appropriate management would substantially improve participant wellbeing and outcomes. After much consideration, TILDA provided feedback to affected participants and their GPs informing them of this condition and subsequently, participants were offered further assessment in a cardiovascular clinic if required. Similarly, the GPs of participants in the MRI sub-study were informed if something was detected during the brain scans and further clinical scans were recommended. Feedback from participants suggests that they were grateful to be informed in these situations and this tended to reinforce their commitment to the study.

The current strategies have maintained the majority of the cohort across three waves, however other approaches could also be considered. Allowing alternative modes of data collection (e.g. telephone or online interviews) where face-to-face interviews are not possible typically increase retention $(16,23)$, although online surveys would be unsuitable for this sample as only 39\% reported having an email address at Wave 3. Offering additional incentives for participants who refuse or who have a higher burden is also an option although there are ethical concerns especially when trying to encourage participation in older frailer adults who are most likely to attrit $(24,25)$. Instead we adapted our interviews and health assessments, allowing participants to maintain their involvement in a way that is more suited to their circumstances. More feedback on health assessment tests and tracking performance across waves will be investigated but will require substantial planning and resources to ensure that meaningful results, implications and recommendations are provided. Further opportunities to engage with participants e.g. providing updates on study findings or tips for successful ageing via text message will also be considered. Despite best efforts to maintain the sample, there will always be some level of attrition, therefore sample weights are derived for the baseline sample and also to account for component non-response (health assessment or SCQ) or attrition from death, loss to follow-up or withdrawal. In addition, the sample will be replenished in Wave 6 focussing on potential participants aged 50-59 years to maintain the original age profile. 


\section{CONCLUSION}

In conclusion, the strategies used in TILDA have helped to successfully retain the majority of the sample over three waves. While we cannot identify the impact of individual strategies, the key strategies include the bond that participants feel with the study, welltrained personnel, rapport between participants and data collectors, inclusion of a health assessment and provision of feedback, detailed tracing procedures, flexibility in data collection and incentives. 


\section{ACKNOWLEDGEMENTS}

We would like to thank the TILDA participants for the time and energy that they have given to the study and for their continued enthusiasm and commitment. We would also like to acknowledge Dr Hilary Cronin, Dr Claire O'Regan, Pauline Walsh and Jacinta O'Grady for their contributions to participant engagement in the study. 


\section{FUNDING}

This work was supported by the Irish Government; The Atlantic Philanthropies; and Irish Life plc. These sponsors played no role in study design; in the collection, analysis and interpretation of data or in the writing of this report. 


\section{REFERENCES}

1. Farrington DP. Longitudinal research strategies: advantages, problems, and prospects. J Am Acad Child Adolesc Psychiatry. 1991;30(3):369-74.

2. Rajulton F. The Fundamentals of Longitudinal Research: An Overview. Canadian Studies in Population. 2001;28(2):169-85.

3. Marcellus L. Are we missing anything? Pursuing research on attrition. Can J Nurs Res. 2004;36(3):82-98.

4. Patel MX, Doku V, Tennakoon L. Challenges in recruitment of research participants. Advances in Psychiatric Treatment. 2003;9(3):229-38.

5. Whelan BJ, Savva GM. Design and methodology of the Irish Longitudinal Study on Ageing. J Am Geriatr Soc. 2013;61(2):12199.

6. Lynn P. Mode-Switch Protocols: How a Seemingly Small Design Difference can affect Attrition Rates and Attrition Bias. 2012.

7. Sullivan CM, Rumptz MH, Campbell R, Eby KK, Davidson WS. Retaning Participants in Longitudinal Community Research: A Comprehensive Protocol. The Journal of Applied Behavioral Science. 1996;32(3):262-76.

8. Hanly MJ, Savva GM, Clifford I, Whelan BJ. Variation in Incentive Effects across Neighbourhoods. Survey Research Methods. 2014;8(1):19-30.

9. Taylor R, Conway L, Calderwood L, Lessof C. Methodology. In: Marmot M, Banks J, Blundell R, Lessof C, Nazroo J, editors. Health, Wealth and Lifestyles of the Older Population in England. London: Institute of Fiscal Studies; 2003. p. 357-74.

10. Scholes S, Cox K, Lessor C. Methodology. In: Banks J, Breeze E, Lessof C, Nazroo J, editors. Living in the 21st century: Older People in England ELSA 2006 (Wave 3). London: Institute for Fiscal Studies; 2008. 
11. Cheshire H, Cox K, Lessof C, Taylor R. Methodology. In: Banks J, Breeze E, Lessof C, Nazroo J, editors. Retirement, Health and Relationships of the Older Population in England: the 2004 English Longitudinal Study of Ageing. London: Institute for Fiscal Studies; 2006. p. 367-83.

12. Hussey D, Lessof C, Ward K, Wood N. Methodology. In: Banks J, Lessof C, Nazroo J, Rogers N, Stafford M, Steptoe A, editors. Financial circumstances, health and wellbeing of the older population in England: The 2008 English Longitudinal Study on Ageing London: The Institute for Fiscal Studies; 2010. p. 386-409.

13. Health and Retirement Survey. Sample Sizes and Response Rates. 2011.

14. Scholes S, Taylor R, Cheshire H, Cox K, Lessof C. Retirement, health and relationships of the older population in England: The 2004 English Longitudinal Study of Ageing. NATCEN, 2008.

15. Scholes S, Medina J, Cheshire H, Cox K, Hacker E, Lessof C. Living in the 21st century: older people in England. The 2006 English Longitudinal Study of Ageing NATCEN, 2009.

16. Booker CL, Harding S, Benzeval M. A systematic review of the effect of retention methods in population-based cohort studies. BMC Public Health. 2011;11(1):1-12.

17. Given BA, Keilman LJ, Collins C, Given CW. Strategies to minimize attrition in longitudinal studies. Nurs Res. 1990;39(3):184-6.

18. Cronin H, O'Regan C, Finucane C, Kearney P, Kenny RA. Health and aging: development of the Irish Longitudinal Study on Ageing health assessment. J Am Geriatr Soc. 2013;61 Suppl 2:S269-78. doi: 10.1111/jgs.12197.:S269-S78.

19. Kearney PM, Cronin H, O'Regan C, Kamiya Y, Whelan BJ, Kenny RA. Comparison of centre and home-based health assessments: early experience from the Irish Longitudinal Study on Ageing (TILDA). Age Ageing. 2011;40(1):85-90.

20. Stein KF, Keller C, Fishstrom A. An unexplored ethical issue in clinical research: disclosure of individual findings in the Creando Posibilidades [Creating Possibilities] study. Res Nurs Health. 2013;36(3):311-9. 
21. Frewen J, Finucane C, Cronin H, Rice C, Kearney PM, Harbison J, et al. Factors that influence awareness and treatment of atrial fibrillation in older adults. QJM. 2013;106(5):415-24.

22. Marini C, De Santis F, Sacco S, Russo T, Olivieri L, Totaro R, et al. Contribution of atrial fibrillation to incidence and outcome of ischemic stroke: results from a populationbased study. Stroke. 2005;36(6):1115-9.

23. Jäckle A, Lynn P, Burton J. Going Online with a Face-to-Face Household Panel: Initial Results from an Experiment on the Understanding Society Innovation Panel. Institute for Social and Economic Research, University of Essex, 2013.

24. Zunzunegui MV, Beland F, Gutierrez-Cuadra P. Loss to follow-up in a longitudinal study on aging in Spain. J Clin Epidemiol. 2001;54(5):501-10.

25. Laurie $H$, Lynn P. The use of respondent incentives on longitudinal surveys. ISER Working Paper Series [Internet]. 2008:[1-32 pp.]. Available from: https://www.iser. essex.ac.uk/files/iser_working_papers/2008-42.pdf. 